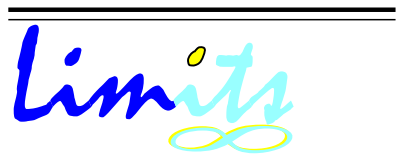

J. Math. and Its Appl.

ISSN : 1829-605X

Vol. 2, No. 1, May. 2005, 17-26

\title{
Aplikasi Fuzzy Analytical Hierarchy Process Dalam Seleksi Karyawan \\ (Studi Kasus: Pemilihan Staf Administrasi Di PT. XYZ)
}

\author{
Mardlijah, Denis Fidita Karya \\ Jurusan Matematika \\ Institut Teknologi Sepuluh Nopember, Surabaya \\ mardlijah@matematika.its.ac.id
}

\begin{abstract}
Abstrak
Pada makalah ini akan dibahas mengenai masalah pengambilan keputusan untuk memilih karyawan terbaik. Adapun metode yang digunakan adalah metode Fuzzy Analytical Hierarchy Process, sebagai pengembangan dari metode Analytical Hierarchy Process Konvensional, untuk menangani permasalahan yang kriteria-kriterianya lebih banyak bersifat subyektif. Pilihan karyawan terbaik dengan Fuzzy Analytical Hierarchy Process menunjukkan bahwa subjektifitas kriteria lebih diperhatikan dibandingkan dengan menggunakan metode Analytical Hierarchy Process Konvensional.
\end{abstract}

Kata kunci:Analytical Hierarchy Process Konvensional,Fuzzy Analytical Hierarchy Process.

\section{Pendahuluan}

Salah satu masalah yang sering muncul pada kehidupan nyata sehari-hari adalah proses penerimaan karyawan baru pada perusahaan. Begitu banyak kriteria 
yang dapat dijadikan faktor untuk mendukung prioritas penentuan pemilihan karyawan tersebut. Permasalahan ini cocok untuk diselesaikan dengan metode Analytical Hierarchy Process (AHP) dan Fuzzy AHP, [2], [5]. Peralatan utama metode ini adalah sebuah hirarki fungsional dengan input utamanya persepsi manusia. Dengan hierarki, suatu masalah kompleks dan tidak terstruktur dipecah kedalam kelompok-kelompoknya dan kemudian kelompok-kelompoknya tersebut diatur menjadi suatu bentuk hirarki.

Adapun rumusan masalah yang dapat diambil yaitu menentukan Consistensi Ratio, Bobot Prior dan Bobot Informasional, dan membandingkan hasil hierarki dari kedua metode tersebut.

\section{Landasan Teori}

Sesuai dengan [2], langkah-langkah dalam metode analitical hierarchy process, meliputi penentuan Pairwise Comparison Matrik dari kriteria, Synthesization, membangun Pairwise Comparison Matrik dari Alternatif, normalisasi, menetapkan vektor pilihan, dan menghitung keseluruhan skor dari setiap alternatif dalam penentuan hierarki.

Dalam fuzzy set, sesuai dengan [2] dan [4] terdapat beberapa definisi secara umum, yaitu jika terdapat himpunan universal $\mathrm{X}$ yang terdiri dari $\mathrm{x}, \mathrm{X}=\mathrm{x}$, maka Fuzzy set A dapat didefinisikan sebagai berikut:

$$
A=\left\{\left(x, \mu_{A}(x)\right) / x \in X\right\}
$$

Variabel Linguistik, adalah penamaan suatu grup yang mewakili suatu keadan atau kondisi tertentu dengan menggunakan bahasa alami, seperti: muda, parobaya, tua.

Variabel fuzzy merupakan variabel yang hendak dibahas dalam suatu sistem fuzzy, contoh: umur, temperatur dsb.

Fungsi keanggotaan merupakan fungsi yang memetakan elemen-elemen suatu himpunan, dalam hal ini disebut himpinan kabur dengan derajat keanggotaannya $\mu_{A}(x)$ disebut fungsi keanggotaan dari himpunan fuzzy A dan dinotasikan sebagai

$$
\mu_{A}: X \rightarrow[0,1]
$$

Sesuai dengan [5] fungsi keanggotaan, terdiri dari bermacam-macam bentuk antara lain:

1. Fungsi keanggotaan berbentuk triangular. Fungsi ini ditentukan oleh tiga parameter $(a, b, c)$ 


$$
\text { Triangle }(x, a, b, c)= \begin{cases}0, & x \leq a \\ \frac{x-a}{b-a}, & a \leq x \leq b \\ \frac{c-x}{c-b}, & b \leq x \leq c \\ 0, & c \leq x\end{cases}
$$

2. Fungsi keanggotaan trapezoidal. Berbentuk trapezoidal dan fungsi ini dipengaruhi oleh empat parameter yaitu $(a, b, c, d)$

$$
\operatorname{Trap}(x: a, b, c, d)= \begin{cases}0, & x \leq a \\ \frac{x-a}{b-a}, & a \leq x \leq b \\ 1, & b \leq x \leq c \\ \frac{d-x}{d-b}, & c \leq x \leq d \\ 0, & d \geq x\end{cases}
$$

3. Fungsi Keanggotaan berbentuk Gaussian Fungsi ini dipengaruhi oleh dua parameter yaitu $c$ dan $\sigma$.

$$
\operatorname{Gaussian}(x, c, \sigma)=e^{\frac{-1}{2}((x-c) \sigma)^{2}}
$$

4. Fungsi keanggotaan Bell Sering juga disebut sebagai Gbell, fungsi ini ditentukan oleh tiga parameter yaitu $(a, b, c)$

$$
\operatorname{Bell}(x ; a, b, c)=\frac{1}{1+\left|\frac{x-c}{a}\right|^{2 b}}
$$

Dalam makalah ini fungsi keanggotaan yang digunakan adalah triangle dan trapezoidal. Menurut [5], Metode Analytical Hierarchy Process (AHP) meliputi :

1. Penilaian Alternatif

Menentukan set penilaian alternatif dalam TFN sesuai variabel Liguistiknya.

2. Pembobotan Kriteria

Menentukan nilai Bobot Prior $\left(w_{i}\right)$ dan Bobot Informasional $\left(\lambda_{i}\right)$.

3. Perhitungan Nilai Akhir

Adapun langkah-langkahnya yaitu:

(a) Menyusun nilai Possibilty $\left(r_{i}\right)$ untuk setiap alternatif

$$
W=\left\{r_{1}^{\prime}, r_{2}^{\prime}, \cdots, r_{n}^{\prime}\right\} \quad \text { dimana } r_{i-1}^{\prime} \leq r_{i}^{\prime} \quad \text { untuk } i=1,2, \cdots, n
$$


(b) Menetapkan Basic Asignment $r_{i}^{\prime}-r_{i-1}^{\prime}=m\left(A_{i}\right)$

(c) Penetapan peringkat fuzzy number didasarkan pada penentuan batas atas $\left(E^{*}\right)$ dan batas bawah $\left(E_{*}\right)$

$$
\begin{aligned}
& E^{*}(f)=\int_{0}^{1} v d F_{*}(v)=\sum_{i=1}^{n}\left(r_{i}-r_{i-1}\right) \max _{y \in A^{*}} f(y) \\
& E_{*}(f)=\int_{0}^{1} v d F^{*}(v)=\sum_{i=1}^{n}\left(r_{i}-r_{i-1}\right) \max _{y \in A_{*}} f(y)
\end{aligned}
$$

dimana:

- $r_{i}-r_{i-1}=m\left(A_{1}\right)=$ Basic Asignment dari $A_{1}$

- $n$ jumlah kriteria

- $f(y)$ nilai alternatif setiap kriteria

- $F^{*}(v)$ batas atas distribusi

- $F_{*}(v)$ batas bawah distribusi

4. Ranking dan Keputusan Akhir Untuk menentukan ranking, terlebih dulu ditentukan center of gravity $(\Phi)$ :

$$
\begin{aligned}
\Delta u & =\frac{(\Phi-b)+\frac{1}{2}(b-a)}{10} \\
\Delta o & =\frac{(b-\Phi)+\frac{1}{2}(c-b)}{10} \\
\Phi_{u M} & =\Phi_{M}-\Delta_{u M}
\end{aligned}
$$

Dengan M fuzzy number yang mana $\Phi>N$. Aturan ranking:

(a) Jika $\Phi N>\Phi u M$ maka $M>N$ (alternatif $M$ lebih baik dari pada $N$ )

(b) Jika $\Phi N<\Phi u M$ dan $\Delta o N<\Delta o M$ maka $N>M$ (alternatif $N$ lebih baik dari pada alternatif $M$ ). Jika tidak, maka alternatif $M$ lebih baik dari pada alternatif $N$. Langkah diatas dilakukan hingga semua alternatif diberi peringkat.

\section{Perancangan Sistem}

Kriteria pemilihan karyawan didasarkan pada kriteria berikut:

1. Kriteria Intelejensi

Kriteria intelejensi terdiri dari subkriteria IQ, Konkrit Pasti, Logis, Konsep Bahasa, dan Konsep Hitung. 
2. Kriteria Kepribadian

Kriteria Kepribadian terdiri dari subkriteria Percaya Diri, Sosialisasi, Hub Personal, Motivasi Berprestasi, Stabilitas Emosi, dan Komunikasi.

3. Kriteria Sikap

Kriteria Sikap terdiri dari subkriteria Adaptasi, Tanggung Jawab, Tekun, Disiplin, dan Kreatif.

4. Kriteria Teknis

Kriteria Teknis terdiri dari subkriteria Kecepatan, Ketelitian, Konsisten, Keandalan, Trouble Shooting, dan Keahlian.

5. Kriteria Manajerial

Kriteria Manajerial terdiri dari subkriteria Perencanaan, Pengorganisasian, Kepemimpinan, dan Pengawasan.

Berikutnya pembentukan matrik parameter TFN. Menentukan Variabel Liguistik dari masing-masing Subkriteria sebagai Matrik parameter pada proses Fuzzyfikasi dengan Fungsi keanggotaan Triangular, dengan bentuk grafik dasar sebagai berikut:

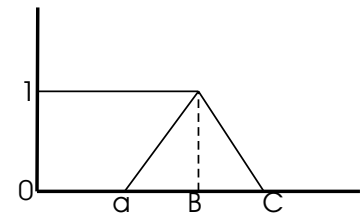

Gambar 1: Grafik Fungsi Keanggotaan Triangular (TPN)

\section{Analisa dan Implementasi}

Langkah penyelesaian metode Analitical hierarchi process adalah sebagai berikut:

1. Membangun matrik pairwise comparison matriks untuk Level 1 (Kriteria) dan Level 2 (Setiap Kriteria),

2. Menjumlahkan nilai setiap kolom dari hasil point 1 .

3. Menormalisasi nilai setiap kolom dari hasil point 1 dengan cara membagi nilai setiap kolom dengan hasil penjumlahan point 2 . 
4. Mencari rata-rata (Prioritas) setiap baris hasil normalisasi sehingga didapat preference vector.

5. Mengalikan hasil rata-rata setiap baris dengan kolom yang bersesuaian pada hasil point 1 .

6. Mencari lambda maksimum $\left(\lambda_{m a k s}\right)$ dan Indeks Konsistensi dari Level 1 dan Level 2 (CI) dengan nilai IR (Indeks Ratio) yang ditetapkan sesuai dengan dimensi atau jumlah kriteria atau subkriteria yang dibandingkan. Dengan rumus dasar

$$
C I=\frac{\lambda_{m a k s}-n}{n-1} \quad \text { dan } \quad C R=\frac{C I}{I R}
$$

Dimana : CR Konsistensi Ratio

7. Mengelompokkan prioritas(Rata-rata) dari semua kriteria (Point 4).

8. Kemudian mengalikan setiap kolom pada hasil point 4 dengan prioritas (Rata-rata) dari Level 1 untuk memperoleh vektor prioritas terbobot.

9. Sekarang pilih dari setiap kolom dengan prioritas tertinggi untuk memperoleh vektor intensitas yang diinginkan.

10. Kemudian jumlahkan baris diatas dan bagi setiap entri dengan jumlah itu untuk mendapatkan vektor yang ternormalisasi.

11. Menetapkan peringkat karyawan yang diamati dengan membentuk matrik yang membandingkan ke-25 karyawan secara berpasangan, berkenaan dengan intensitas sifat yang paling disenangi.

12. Kelompokkan prioritas-prioritas karyawan yang berkenaan dengan setiap intensitas sifat yang disenangi dalam kolom-kolom, dan masukkan prioritasprioritas yang dinormalisasi di atas kolom itu.

13. Lalu kalikan setiap kolom dengan prioritas yang dinormalisasi (Point 10) dari sifat yang sesuai untuk memperoleh vektor prioritas terbobot bagi intensitas sifat yang disenangi untuk setiap calon karyawan.

14. Lalu jumlahkan masing-masing baris untuk memperoleh prioritas menyeluruh dari 25 calon karyawan. Sintesis ini menghasilkan prioritas berikut: 
Tabel 1. Hasil Ranking dengan AHP

\begin{tabular}{|c|c|c||c|c|c|}
\hline No & Nama & Nilai Prioritas & No & Nama & Nilai Prioritas \\
\hline \hline 1 & $\mathrm{C}$ & 0.0503 & 14 & $\mathrm{Y}$ & 0.0386 \\
\hline 2 & $\mathrm{I}$ & 0.0489 & 15 & $\mathrm{R}$ & 0.0384 \\
\hline 3 & $\mathrm{D}$ & 0.0479 & 16 & $\mathrm{E}$ & 0.0377 \\
\hline 4 & $\mathrm{H}$ & 0.0479 & 17 & $\mathrm{~T}$ & 0.0376 \\
\hline 5 & $\mathrm{Q}$ & 0.0472 & 18 & $\mathrm{~K}$ & 0.0368 \\
\hline 6 & $\mathrm{~F}$ & 0.0462 & 19 & $\mathrm{~N}$ & 0.0364 \\
\hline 7 & $\mathrm{X}$ & 0.0447 & 20 & $\mathrm{~V}$ & 0.0356 \\
\hline 8 & $\mathrm{~B}$ & 0.0443 & 21 & $\mathrm{O}$ & 0.0351 \\
\hline 9 & $\mathrm{~A}$ & 0.0442 & 22 & $\mathrm{U}$ & 0.0348 \\
\hline 10 & $\mathrm{~L}$ & 0.0439 & 23 & $\mathrm{~W}$ & 0.0294 \\
\hline 11 & $\mathrm{~J}$ & 0.0414 & 24 & $\mathrm{~S}$ & 0.0287 \\
\hline 12 & $\mathrm{M}$ & 0.0396 & 25 & $\mathrm{P}$ & 0.0281 \\
\hline 13 & $\mathrm{G}$ & 0.0390 & & & \\
\hline \hline
\end{tabular}

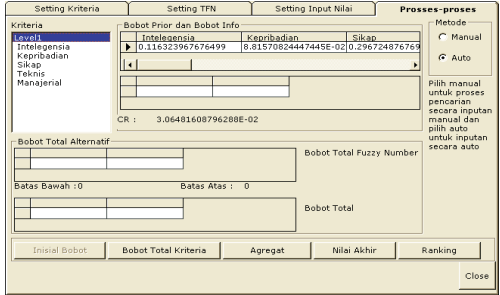

Gambar 2: Bobot Prior Level 1

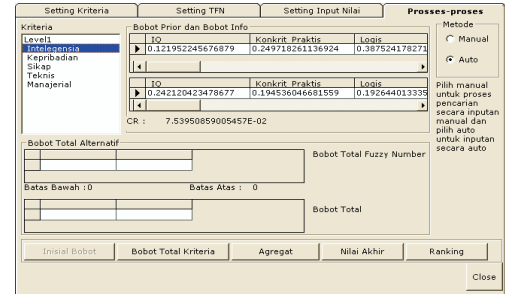

Gambar 3: Bobot Kriteria Inteljensi

Berdasarkan hasil akhir diatas dapat ditetapkan Rangking (Hierarchy) dari 25 alternatif karyawan. Jadi dengan metode AHP Konvensional ditetapkan bahwa karyawan $\mathrm{C}$ adalah alternatif terbaik sesuai keinginan perusahaan xyz.

Berikutnya akan dibahas metode Fuzzy Analitical hierarchi process. Langkahlangkah metode Fuzzy Analitical hierarchi process meliputi:

1. Data Penilaian Alternatif Penilaian alternatif terhadap setiap kriteria, dimana ditentukan oleh perusahaan xyz terhadap 25 alternatif karyawan dalam suatu Triangular Fuzzy Number (TFN).

2. Hasil Perhitungan Bobot Kriteria Hasil perhitungan bobot Prior dan Informasional dari Level 1 dan Level 2 sebagai berikut:

(a) Bobot Prior (wi) Level 1 dari kriteria yang dibandingkan 


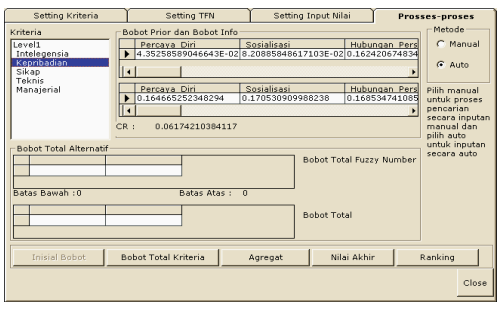

Gambar 4: Bobot Kriteria Kepribadian

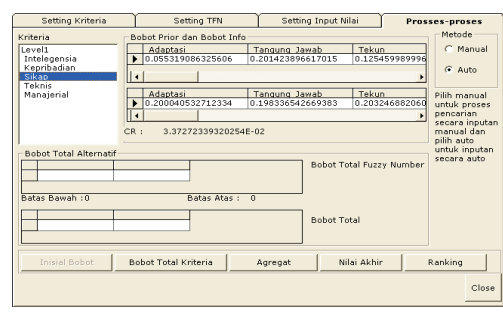

Gambar 5: Bobot Kriteria Sikap

(b) Bobot Prior dan bobot informasional dari kriteria Intelejensia

(c) Bobot Prior dan bobot informasional dari kriteria Kepribadian

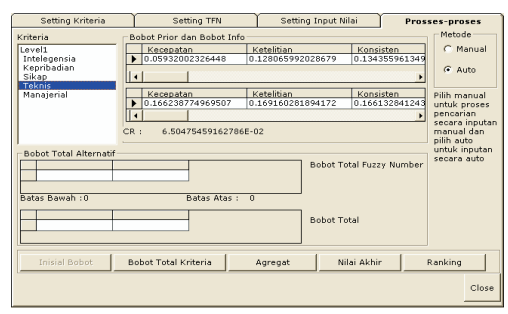

Gambar 6: Bobot Kriteria Teknis

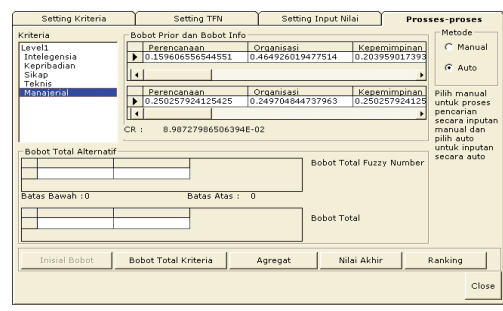

Gambar 7: Bobot Kriteria Manajerial

(d) Bobot Prior dan bobot informasional dari kriteria Sikap

(e) Bobot Prior dan bobot informasional dari kriteria Teknis

(f) Bobot Prior dan bobot informasional dari kriteria Manajerial

3. Hasil Perhitungan Nilai Akhir Pada proses ini dilakukan berbagai perhitungan diantaranya perhitungan nilai batas atas dan nilai batas bawah dengan integral Lebesque-Stieltjes ([5]), perhitungan bobot total kriteria awal, dan bobot total akhir setelah difuzzyfikasi. Hasil perhitungan nilai akhir diatas dapat dilihat dibawah ini:

4. Hasil Ranking Nilai Akhir Dari proses perhitungan bobot total akhir hasil fuzzyfikasi, dapat kita tentukan Hierarchy (Ranking) sebagai keputusan akhir dalam menentukan seleksi karyawan yang terbaik sesuai keinginan perusahaan xyz terhadap 25 alternatif karyawan diperoleh karyawan $\mathrm{F}$ adalah alternatif Terbaik dari 24 karyawan yang lain. Untuk lebih jelasnya dapat dilihat pada Gambar 9 dibawah ini: 


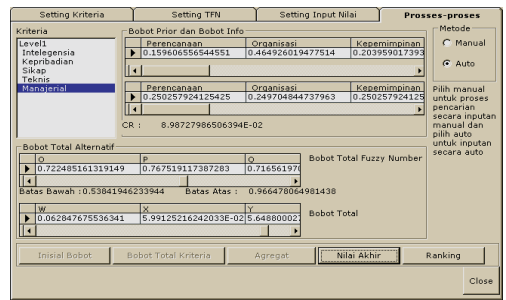

Gambar 8: Hasil Perhitungan Akhir

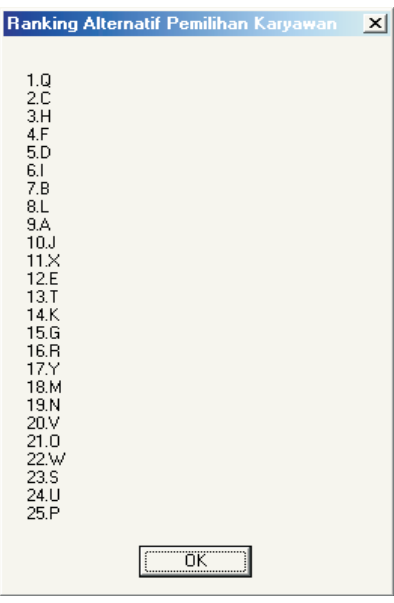

Gambar 9: Hasil Ranking

\section{Kesimpulan dan Saran}

Kesimpulan yang dapat ditarik dari makalah ini adalah:

1. Bobot Total Alternatif dari kedua metode mempunyai nilai berbeda, metode AHP Konvensional [C, I, D, H, Q, F, X, B, A, L, J, M, G, Y, R, E, T, K, N, V, O, U, W, S, P]; sedangkan metode Fuzzy AHP [Q, C, H, F, D, I, B, L, A, J, X, E, T, K, G, R, Y, M, N, V, O, W, S, U, P].

2. Ranking (Hierarchy) nilai akhir dari kedua metode tersebut mempunyai urutan yang berbeda, karena nilai bobot total alternatifnya berbeda;

3. Pada seleksi karyawan ini alternatif karyawan yang terbaik adalah Karyawan C (metode AHP Konvensional) dan Karyawan Q (metode Fuzzy AHP) karena memiliki nilai bobot total alternatifnya tertinggi. Perbedaan ini dikarenakan fuzzy AHP lebih memperhatikan faktor subyektifitas dengan adanya perhitungan bobot informasional, sedangkan AHP Konvensional tidak;

4. Pada metode Fuzzy AHP memperhitungkan informasional weight sedangkan pada metode AHP Konvensional hanya pada perhitungan Prior Weight.

Adapun saran yang dapat ditulis disini yang berkaitan dengan permasalahan ini adalah:

1. Bagi peneliti lain diharapkan mampu mengembangkan teori Fuzzy AHP dalam segenap bidang bukan cuma pada seleksi karyawan semata; 
2. Selain itu juga dapat lebih mengembangkan dengan menambah jumlah alternatif karyawan, metode Lain yang ada hubungannya dengan permasalahan ini;

3. Bagi segenap Perusahaan untuk memanfaatkan metode Fuzzy AHP atau AHP Konvensional untuk memantapkan dan mempercepat proses penyeleksian karyawan baru;

4. Mampu membandingkan antara metode yang satu dengan metode yang lainnya baik yang ada hubungannya dengan permasalahan ini ataupun permasalahan lain yang akan diteliti;

\section{Pustaka}

[1] Permadi, B., (1992),Analytical Hierarchy Process, PAU-EK-UI, Jakarta.

[2] Saaty, T. L., (1993), Pengambilan Keputusan Bagi Para Pemimpin, Proses Hirarki Analitik Unit1 : Pengambilan Keputusan dalam situasi yang kompleks, PT. Pustaka Binaman Pressindo.

[3] Zimmermann, H. J., (1996), Fuzzy Set Theory-and Its Application, Third Edition, Kluwer Academic Publishers, Boston/Dordrecht/London.

[4] Purnomo, H., (2004),Aplikasi Logika Fuzzy Untuk Pendukung Keputusan, Edisi Pertama, Graha Ilmu, Yogyakarta.

[5] http://www.superdecisions.com/saaty/ISAHP2005 /Papers/SuryadiK_Malvinas _ Mangkoesubroto _Yudhistira_ConjointAHP.pdf 